\title{
UNIDADES DE CONSERVAÇÃO BRASILEIRAS: DESAFIOS DA GESTÃO
}

Nome do Autor (a) Principal

\section{GABRIELA FERREIRA PIRES}

Nome (s) do Orientador (a) (s)

FERNANDO PROTTI BUENO

Instituição ou Empresa

UNIVERSIDADE ESTADUAL PAULISTA - UNESP

E-mail de contato: gabyf.p@hotmail.com

Palavras-chave: Unidades de conservação. Desafios. Gestão.

\section{INTRODUÇÃO}

Decretar determinadas porções territoriais nacionais como unidade de conservação não basta para protegê-las, pois é notável que essas áreas continuam sofrendo diversas ameaças à sua biodiversidade, por isso existe a "necessidade de aprimorar a gestão ou manejo dessas unidades para que elas possam cumprir a missão para a qual foram criadas" (ARAUJO, 2012, p.191).

Há a necessidade de se estabelecer um suporte adequado para a gestão das unidades de conservação, a qual está vinculada a diversos aspectos técnicos, políticos e econômicos tais como planejamento, capacidade institucional, conhecimentos gerados e disponíveis, aspectos legais, programas de desenvolvimento regional e educação ambiental, entre outros, para que assim os objetivos de uma unidade de conservação de se garantir a preservação da diversidade biologia, promover o desenvolvimento sustentável e proteger as comunidades tradicionais e suas culturas sejam alcançados e que o uso público dessas áreas de forma responsável traga o aumento do fluxo de visitantes, e, consequentemente, as pessoas passem a valorizar as belezas naturais brasileiras, de modo a compreender sua importância para a humanidade. 
De acordo Rylands e Bradon (2005) ao Brasil confere-se uma responsabilidade global muito grande, pois precisa proteger três grandes regiões naturais: a Amazônia, o Pantanal e a Caatinga, e ainda dois hotspots de biodiversidade: a Mata Atlântica e o Cerrado. Araújo (2012) diz que essa proteção se deve ao fato da biodiversidade brasileira ser um importante componente dos sistemas ecológicos, dos quais deriva uma série de bens e serviços que contribuem decisivamente para o bem-estar da humanidade.

Entretanto, Nagagata (2006) alega que as unidades de conservação sofrem inúmeras dificuldades como, por exemplo, a falta de recursos econômicos para promover estudos, contratar técnicos, administrar a área entre outros. A relação entre a população e a unidade de conservação, normalmente se caracteriza pela falta de consciência sobre a importância das áreas protegidas devido ao pouco envolvimento entre estes.

Rylands e Bradon (2005) afirmam que para que as unidades de conservação tenham êxito são necessárias iniciativas capazes de fortalecer o manejo das áreas protegidas para uma efetiva conservação da biodiversidade, além de fortalecer alianças com outros gestores de terra, para assim assegurar a viabilidade a longo prazo das unidades de conservação tanto federais e quanto estaduais do Brasil. Brito (2003) aponta que as dificuldades financeiras e de recursos humanos, imprimem especial dificuldades à efetiva implantação das unidades de conservação, além disso, coloca como um problema central à degradação das unidades a inexistência de políticas para a gestão das unidades e a desestruturação dos órgãos públicos responsáveis.

Entre inúmeras melhorias e possibilidades que podem ser pensadas e bem planejadas dentro da categoria de parques nacionais, Mercante (2007) cita algumas, tais como: regulamentar a visitação, dotar ou melhorar a infraestrutura dos parques, controlar a arrecadação, capacitar o pessoal, incentivar o trabalho voluntário, promover a articulação com outros órgãos e instituições, sobretudo do setor de turismo.

Existem vários desafios que as unidades de conservação brasileiras, muitas vezes decorrentes de uma gestão deficiente, e para que esta seja gerida de forma responsável é preciso de um bom planejamento meios para cumprir suas devidas missões. O Parque Nacional do Iguaçu é mencionado como passível de ser 
considerado enquanto um modelo de unidade de conservação gerenciada adequadamente, por conta de seu alto fluxo de visitantes anualmente, principalmente no ano de 2015.

\section{OBJETIVO}

Pretende-se com este trabalho apresentar alguns resultados preliminares acerca da discussão sobre os desafios que as unidades de conservação brasileiras sofrem em relação as formas de gerenciamento, de modo a apontar um exemplo de unidade que consegue ser gerida de modo mais adequado, gerando uma demanda favorável por meio de uma gestão responsável.

\section{METODOLOGIA}

A pesquisa se utilizou do método dedutivo e das técnicas de pesquisa bibliográfica e documental para coleta e análise de dados.

\section{RESULTADOS}

Passível de ser considerada enquanto um modelo de unidade de conservação gerenciada adequadamente se tem o Parque Nacional do Iguaçu, dirigido pelo Instituto Chico Mendes de Conservação da Biodiversidade (ICMBio), órgão federal responsável pela gestão das Unidades de Conservação do Brasil. O Parna do Iguaçu é um exemplo de integração entre a conservação e o uso sustentável de seus recursos naturais. O parque foi criado em 1939 e abriga o maior remanescente de Mata Atlântica (floresta estacional semidecídua) da região sul do país (ICMBio, 2015).

Segundo os dados do parque, seu movimento de visitação tem crescido mesmo após haver o recorde de visitantes no ano de 2011 com a entrada de cerca de 1,4 milhões de visitantes. No primeiro mês do ano de 2012, a unidade recebeu 198.521 visitantes, $8,75 \%$ a mais do que o mesmo período do ano de 2011 . O visitante brasileiro contribui com $62 \%$ do público geral e os visitantes de outros países do bloco do Mercosul (Argentina, Paraguai e Uruguai) correspondem a 19\%, e os outros estrangeiros completam os dados com 19\% do total (ICMBio, 2015). Esse 
intenso fluxo de visitantes ocorre obviamente devido as Cataratas, mas deve-se pontuar que o atrativo turístico está interligado a um modelo de gestão concessionado e terceirizado, que contribui significativamente para esse fluxo elevado.

No ano de 2015 o Parque Nacional do Iguaçu registrou sua melhor visitação trimestral desde 1980. De janeiro a março, a unidade recebeu 450.060 pessoas. $O$ fluxo de turistas foi $4,3 \%$ maior que no mesmo período de 2014 , quando ingressaram 431.359 e em 2013 o número foi de 430.557 visitantes. Esse andamento positivo do Parque é resultado de uma responsável gestão, organização e planejamento.

A gestão desse grande fluxo de visitantes, busca compreender o perfil dos turistas, de modo a possibilitar a qualidade de atendimento, e, além disso, investem em ações de divulgação, o que têm auxiliado o parque a estabelecer sucessivos recordes anuais de visitação.

A compreensão do Parque enquanto uma referência nacional, se dá pelo fato de que o mesmo cumpre para com seus objetivos, sendo estes o de implantar e operar as atrações/atividades proporcionando uma visitação de melhor qualidade/experiência ao visitante. Além disso, o sucesso de gestão do parque não é apenas relativo ao grande fluxo de visitantes e sua forma de manejo, mas também está voltada a relação estabelecida com a comunidade e o contato junto aos turistas. É relevante mencionar algumas das formas com que a gestão do parque atua para que este possa ser considerado um modelo em se tratando de unidades de conservação, tais como: a elaboração de projetos de potencialização de visitação, dentro das normas que regem os Parques Nacionais Brasileiros e o Plano de Manejo do Parque Nacional do Iguaçu, a renovação e a ampliação da infraestrutura de atendimento ao visitante por meio de investimentos de capital privado, melhorias ao aproveitamento do potencial de visitação, promoção da preservação e da educação ambiental, realização de treinamento ambiental (palestras sobre noções básicas de unidades de conservação), adequação da postura e do comportamento dentro de uma unidade de conservação, de funcionários e terceirizados, tratamento de resíduos líquidos nas estações de tratamento de esgoto (ETE) e a promoção da coleta seletiva de resíduos, para reciclagem. Assim, esses são alguns dos exemplos de ações geridas pela unidade de conservação em questão. 


\section{CONCLUSÃO}

É possível notar que as unidades de conservação brasileiras enfrentam inúmeros desafios relacionados a gestão, porém deve-se buscar reverter ou minimizar esta situação já que o país é contemplado com biomas de grande relevância para humanidade, e vale ressaltar que uma unidade de conservação bem manejada e monitorada é capaz de minimizar impactos ambientais e culturais se tratando das comunidades locais.

Pode observar que de acordo com os desafios que ocorrem em muitas unidades de conservação, que esses são minimizados graças a uma gestão competente, que utiliza de serviços terceirizados no serviço de visitação e em atrativos turísticos, isso faz com que o parque arrecade receita que é revertida em melhorias para o parque em geral, como, por exemplo, na implementação, manutenção e gestão da própria unidade.

Os desafios às unidades de conservação são um conjunto complexo de fatores, que contribuem para a gestão precária das unidades de conservação brasileiras. Para reversão dessa situação, é preciso que haja a compreensão dos fatores de uma forma geral, para que se possa planejar melhorias gerenciais.

Portanto, é notável que existem várias soluções que se planejadas de forma responsável, buscando diversos meios para alcançar a eficácia da gestão, as unidades de conservação brasileiras podem vir a se fortalecer e, consequentemente, poder aumentar o fluxo de visitantes.

\section{REFERÊNCIAS}

ARAUJO, Marcos Antonio Reis. Unidades de conservação: importância e história no mundo. In: NEXUS (Org.). Unidades de conservação no Brasil: o caminho da gestão para resultados. São Carlos: RiMa Editora, 2012, p. 25-50.

BRITO, Maria Cecília Wey de. Unidades de conservação: intenções e resultados. 2ed. São Paulo: Annablume: Fapesp, 2003.

ICMBio. Parque Nacional do Iguaçu. Disponível em: $\leq$ http://www.icmbio.gov.br/parnaiguacu/biodiversidade/14-fauna.html $>$. Acesso em: 21 de maio de 2015. 
MERCADANTE, Maurício. Avanços na implementação dos Snuc e desafios para o futuro. In: NUNES, M.; TAKAHASHI, L. Y.; THEULEN, V. Unidades de conservação: atualidades e tendências. Curitiba, Fundação O Boticário de Proteção à Natureza, 2007, p. x-x.

NAGAGATA, Elizabeth. A importância da educação ambiental como ferramenta adicional a programas de conservação. In: ROCHA, C. F. D.; et. al. Biologia da conservação: essências. São Carlos: Rima, 2006, p. 583-584.

RYLANDS, Anthony; BRADON, Katrina. Unidades de conservação brasileiras. Megadiversidade. v.1, n.1, julho/2005. 